\title{
Effect of biodiesel on particulate numbers and composition emitted from turbocharged diesel engine
}

\author{
A. N. Shah · G. Yun-shan - F. H. Shah • \\ H. U. Mughal $\cdot$ Z. u. Rahman $\cdot$ A. Naveed
}

Received: 22 September 2012/Revised: 11 January 2013/ Accepted: 4 February 2013/Published online: 26 February 2013

(C) Islamic Azad University (IAU) 2013

\begin{abstract}
In present study a turbocharged, medium duty compression ignition engine was alternatively fuelled with biodiesel to investigate the changes in particulate matter composition, relative to that taken with diesel fuel. The engine was operated on an AC electrical dynamometer in accordance with an 8-mode, steady-state cycle. The numbers of particles were estimated through electrical low pressure impactor, while sulfates and trace metals were analyzed by ion chromatography and inductively coupled plasma-atomic emission spectroscopy, respectively. Nitric oxides and nitrogen dioxides were measured separately using SEMTECH-DS. Experimental results revealed that, on account of elevated ratios of nitrogen dioxide to nitrogen oxides, mean accumulation mode particles were $42 \%$ lower with biodiesel. On the other hand, nuclei mode particles were higher with biodiesel, owing to heterogeneous nucleation and accounting for an increase in sulfate emissions up to $8 \%$ with biodiesel as compared to diesel. On the average, trace metal emissions were significantly reduced showing 65-85.4\% reduction rates with biodiesel, relative to its counterpart. Further to this, individual congeners such as iron, calcium, and sodium were the predominant
\end{abstract}

A. N. Shah · F. H. Shah · H. U. Mughal · A. Naveed

Department of Mechanical Engineering,

University of Engineering and Technology,

Lahore 54000, Pakistan

A. N. Shah $(\varangle) \cdot$ G. Yun-shan

National Laboratory of Auto Performance and Emission Test,

School of Mechanical and Vehicular Engineering,

Beijing Institute of Technology, Beijing 100081, China

e-mail: anaeems@uet.edu.pk

Z. u. Rahman

Department of Chemical Engineering, University of Engineering and Technology, Lahore 54000, Pakistan elements of the trace metals emitted from engine. The mean relative decrease in iron and calcium was $89-97.8$ and $77.6-87 \%$, respectively, while the relative rise in sodium was in the range of $29-46 \%$ with biodiesel. Further, elements such as zinc, chromium, and aluminum showed substantial abatement, whereas potassium, magnesium, and manganese exhibited irregular trends on account of variable engine loads and speeds during the various modes of cycle.

Keywords Nanoparticles - Particulate matter - Sulfates · Trace metals · Unregulated emissions

\section{Introduction}

During last few decades, rapidly depleting fuel reserves and ever tight emission regulations are jeopardizing the diesel engine technology. Consequently, the scientists and researchers are working hard for the survival of such an efficient and reliable prime mover.

Among various alternative fuels, biodiesel has received a considerable attention of scientific community due to its nominal sulfur content, renewable character, oxygen enrichment and relatively higher cetane number. It has the potential to reduce most of the gaseous regulated pollutants such as total hydrocarbons (THC) and carbon monoxide (CO) emissions on account of more complete combustion (Lapuerta et al. 2002; Turrio-Baldassarri et al. 2004; He et al. 2009). Unfortunately, there is conflict and inconsistency in the literature regarding control of nitrogen oxides $\left(\mathrm{NO}_{\mathrm{x}}\right)$ with biodiesel relative to diesel fuel (Dorado et al. 2003; Agarwal et al. 2006; Szybist et al. 2007; Agarwal and Rajamanoharan 2009). However, particulate matter (PM), an important class of regulated emissions gets abated by this renewable fuel (He et al. 2009). 
Smoke opacity which is the direct measure of smoke and soot is significantly decreased with biodiesel (Agarwal and Das 2001; Lapuerta et al. 2008). Soot, constituting a major portion of PM, is basically black carbon comprising a large number of tiny particles with diameter less than $100 \mathrm{~nm}$ (Kittelson et al. 2006). It has been reported that oxidation rate of soot is higher in case of biodiesel relative to commercial diesel (Song et al. 2006). Jung et al. (2006) are of the view that soot-oxidation velocity is about 6 times higher with biodiesel as compared to petroleum diesel. Owing to the scarcity of aromatic hydrocarbons, unregulated pollutants such as polycyclic aromatic hydrocarbons (PAHs), carbonyls and volatile organic compounds (VOCs) are substantially reduced with biodiesel (Lin et al. 2006; Jha et al. 2008). Higher thermal efficiency, lower brake specific energy consumption (BSEC) endorse the better performance of engine fuelled with biodiesel (Agarwal and Das 2001).

$\mathrm{PM}$, in general, consists of trace elements or ashes, sulfates, soluble organic fraction (SOF) or volatile organic fraction (VOF) and carbon soot (He et al. 2009). According to Agarwal (2007), PM is composed largely of unburnt lubricating oil and elemental carbon with respective contribution of 40 and $31 \%$. Sulfates and unburnt fuel contribute to 14 and $7 \%$, respectively, while the remaining $8 \%$ of PM is shared by metals and other substances. As indicated by name, trace metals are only in traces or small amounts resulted from the reaction of elements in lube oil or/and fuel with the gaseous sulfite at elevated temperature in the combustion chamber of engine (Lim et al. 2007). At higher combustion temperatures, fuel sulfur is converted to sulfur dioxide $\left(\mathrm{SO}_{2}\right)$, then to sulfur trioxide $\left(\mathrm{SO}_{3}\right)$, and finally to sulfuric acid $\left(\mathrm{H}_{2} \mathrm{SO}_{4}\right)$ in the presence of water (Schneider et al. 2005). Further, the sulfuric acid nuclei may promote the adsorption phenomenon which leads to the formation of SOF or VOF of PM (Armas et al. 2008).

$\mathrm{PM}$ emanated from diesel engine consists predominantly of nuclei, accumulation, and coarse mode particles depending on their diametric ranges (Liu et al. 2011). They are affected by various factors such as sampling methodology, engine type, fuel composition, lubricating oil, and driving cycle (Zhao et al. 2010). The nuclei mode particles with diameter in the range of $5-50 \mathrm{~nm}$ contain a major portion of particles in number, while accumulation mode particles with diameter 50-1000 nm include most of the PM mass. Further, the coarse mode particles with diameter larger than $2.5 \mu \mathrm{m}$ make up only less than $10 \%$ of total particle mass (Wong et al. 2003). As nuclei mode particles are relatively large in number but smaller in size, their probability of inhalation is increased due to their suspension in the air over larger distances for longer intervals of time. This may further lead to inflammation, lung cancer, and some other respiratory diseases (Donaldson et al. 1998).
Moreover, the carcinogenicity and toxicity of PM increases with decreasing particle diameter into nano-size range (Sierra Club of Canada, Eastern Canada Chapter 2003). In the view point of some researchers, ultrafine particles $\left(D_{\mathrm{p}}<100 \mathrm{~nm}\right)$ have the ability to be absorbed or adsorb on organic molecules and to attack the human cardiovascular and pulmonary systems by penetration (Frampton 2001; Nemmar et al. 2002). Therefore, it is deemed that future emission legislations on PM will be extended to number of particles' (NPs) measurements as well.

Although a number of studies focused on regulated emissions have unanimously established that PM emissions decrease with biodiesel, limited and discordant findings have been reported on nuclei and accumulation mode particles emitted from biodiesel fuelled engine. Moreover, complete physical and chemical characterization of PM under different operating conditions is still in infancy. Particularly, comparative characterization of PM emissions with biodiesel using the Chinese steady-state test has not yet been addressed to best of authors' knowledge. The objective of present work is to characterize the PM emissions in terms of nuclei and accumulation mode particles, sulfates and trace metal emissions (TME) from turbocharged diesel engine alternatively fuelled with biodiesel, and then to compare them with baseline measurements. The present work will help to gain deep insight into the role of biodiesel in the changes of PM composition if any, relative to conventional diesel fuel.

Current study is the part of research work carried out in Beijing Institute of Technology (BIT) for the pursuance of doctoral degree. The experiments were performed in the Laboratory of Auto Performance and Emission Test, School of Mechanical engineering BIT Beijing, PR China, from October to November 2009.

The structure of present paper is as follows: "Introduction" section presents the literature reviews to introduce the biodiesel effect on the various pollutants and then the composition of PM emissions. "Materials and methods" describe the test bed, fuels, lubricant and driving cycle along with sampling methodology, pollutants analysis, and finally quality assurance of the study. Results and their discussions have been given in section "Results and discussions". "Conclusion" section covers the conclusions of the study.

\section{Materials and methods}

Test bench, fuels and driving cycle

A medium duty $4.752 \mathrm{~L}$ direct injection turbocharged diesel engine was coupled with an AC electrical dynamometer (Schenck HT350, Germany) on a test bench. 
The engine is intercooled having four cylinders with bore and stroke of 110 and $125 \mathrm{~mm}$, respectively. The injector consists of six nozzles/holes, each of which has a diameter of $0.23 \mathrm{~mm}$. The compression ratio of the engine is $16.8: 1$, while maximum power and torque are $117 \mathrm{~kW}$ and $580 \mathrm{Nm}$ at 2,300 and 1,400 $\mathrm{r} / \mathrm{min}$, respectively. The engine was fuelled first with locally available commercial diesel for baseline measurements, and then with biodiesel produced from soybean oil having properties listed in Table 1. The cycle of operation was in accordance with the Chinese 8 Mode steady-state test recognized as ISO 8178 Type C1 (He et al. 2009). The engine was run at 100, 75, 50, and $10 \%$ of full load at $2,300 \mathrm{r} / \mathrm{min}$ for $1-4$ modes, while at 100,75 , and $50 \%$ of full load at $1,400 \mathrm{r} / \mathrm{min}$ for $5-7$ modes. Mode 8 is recognized as an idle mode. Figure 1 shows the schematic of experimental bench. The lubricating oil composed of 0.6, 1.6, 3.3, 15.3, 63.9, 353, and $>1,000 \mathrm{ppm}$ of iron $(\mathrm{Fe})$, aluminum $(\mathrm{Al})$, sodium $(\mathrm{Na})$, magnesium $(\mathrm{Mg})$, molybdenum (Mo), zinc ( $\mathrm{Zn})$, and calcium $(\mathrm{Ca})$, respectively.

\section{Sampling and analysis of pollutants}

The exhaust was sampled at two stages. At the first stage, nitric oxide (NO) and nitrogen dioxide $\left(\mathrm{NO}_{2}\right)$ were measured separately using SEMTECH-DS (USA). The second stage exhaust was further split into two parts. First part was used to estimate the nuclei and accumulation mode particles by passing it through two tandem ejector diluters in series to simulate the first stage at $200{ }^{\circ} \mathrm{C}$ and second stage at ambient temperature with a dilution ratio of almost 8 at each stage. After dilution, this part of exhaust was passed through an electrical low pressure impactor (ELPI), made of Dekati company Finland, consisting of a corona charger, a multi-channel electrometer, and a 12-stage cascade impactor. The volume flow rate of exhaust was controlled through a sampling pump at the rate of $10 \mathrm{~L} / \mathrm{min}$. The ELPI measures number-size distribution of particles in 13 cut sizes (i.e., 0.007, 0.029, 0.057, 0.101, 0.165, 0.255, $0.393,0.637,0.99,1.61,2.46,3.97$, and $10.15 \mu \mathrm{m}$ ) with size range of $0.03-10 \mu \mathrm{m}$.
The second part of sampled exhaust, on the other hand, was passed through an ejector diluter similar to that used for ELPI but at $100{ }^{\circ} \mathrm{C}$ to trap the pollutants in Teflon filter membrane (Pall Corporation) for the measuring of TME and sulfates. The filter was $47 \mathrm{~mm}$ in diameter and $0.2 \mu \mathrm{m}$ in pore size, while the volume flow rate of the sampled material was kept constant at $80 \mathrm{~L} / \mathrm{min}$ through a batteryoperated sampling pump. The sampled filters were, then stored till further processing.

Each filter was divided into two equal parts of almost same size. One of them was further cut into several pieces and put into Teflon vessel. The sampled material was immersed into $2 \mathrm{~mL}$ nitric acid $\left(\mathrm{HNO}_{3}\right)$ for $5 \mathrm{~min}$ and then dissolved into $1 \mathrm{~mL}$ highly purified hydrochloric acid $(\mathrm{HCl})$. Finally, a solution of about $10 \mathrm{~mL}$ was prepared in a standard flask after the digestion of filtered material. The inductively coupled plasma (ICP)-atomic emission spectroscopy (VARIN VISTA-MPX) was used for the analysis of TME. Following trace metals were resulted from the ICP analysis: $\mathrm{Na}, \mathrm{Mg}, \mathrm{Al}, \mathrm{Ca}, \mathrm{Fe}, \mathrm{Zn}$, potassium $(\mathrm{K})$, titanium $(\mathrm{Ti})$, chromium $(\mathrm{Cr})$, sulfur $(\mathrm{S})$, manganese $(\mathrm{Mn})$, copper $(\mathrm{Cu})$, strontium $(\mathrm{Sr})$, lead $(\mathrm{Pb})$, and nickel $(\mathrm{Ni})$.

The second half part of the filter was also cut into several pieces which were taken into a centrifuge tube. About $15 \mathrm{~mL}$ of highly purified and deionized water was used to immerse the sampled material which was then sonicated for $20 \mathrm{~min}$. A microcellular membrane filter was used to purify the extract (Zhao et al. 2010). Above procedure was repeated once again to get another extract, and finally the two extracts were mixed together for the subsequent analysis. The sulfate emissions were quantified by ion chromatography (Dionex, USA).

\section{Quality control/quality assurance (QC/QA)}

Field blanks levels at the sampling site were less than $4 \%$ of the concentrations in the samples. These field blanks were stored and their effects were subtracted from the final results. The mean recovery of PM congeners was $(89 \pm 10) \%$ in the samples $(n=4)$ and that of TME congeners up to $(83 \pm 13) \%$ in the samples $(n=3)$.

Table 1 Fuel Properties and corresponding test method

\begin{tabular}{|c|c|c|c|c|}
\hline Parameter & Diesel & Biodiesel & Method $^{\mathrm{a}}$ & $\approx \mathrm{ASTM}$ \\
\hline Sulfur content (ppm) & 350 & 160 & GB/T380 & D4294 \\
\hline Density $\left(\mathrm{kg} / \mathrm{m}^{3}\right)$ at $20^{\circ} \mathrm{C}$ & 841 & 875 & GB/T1884-85 & D1298/4052 \\
\hline Cetane number & 52 & 60.1 & GB/T386 & D6890 \\
\hline Viscosity $\left(\mathrm{mm}^{2} / \mathrm{s}\right)$ at $20^{\circ} \mathrm{C}$ & 4 & 7.1 & GB/T265 & D445 \\
\hline $\mathrm{C}: \mathrm{H}$ & $87: 13$ & $77: 12$ & SH/T 0656-1998 & \\
\hline Oxygen content (wt \%) & 0 & 11 & & \\
\hline Lower calorific value $(\mathrm{MJ} / \mathrm{kg})$ & 42.8 & 37.3 & & \\
\hline
\end{tabular}

${ }^{a}$ Standard method used in China 


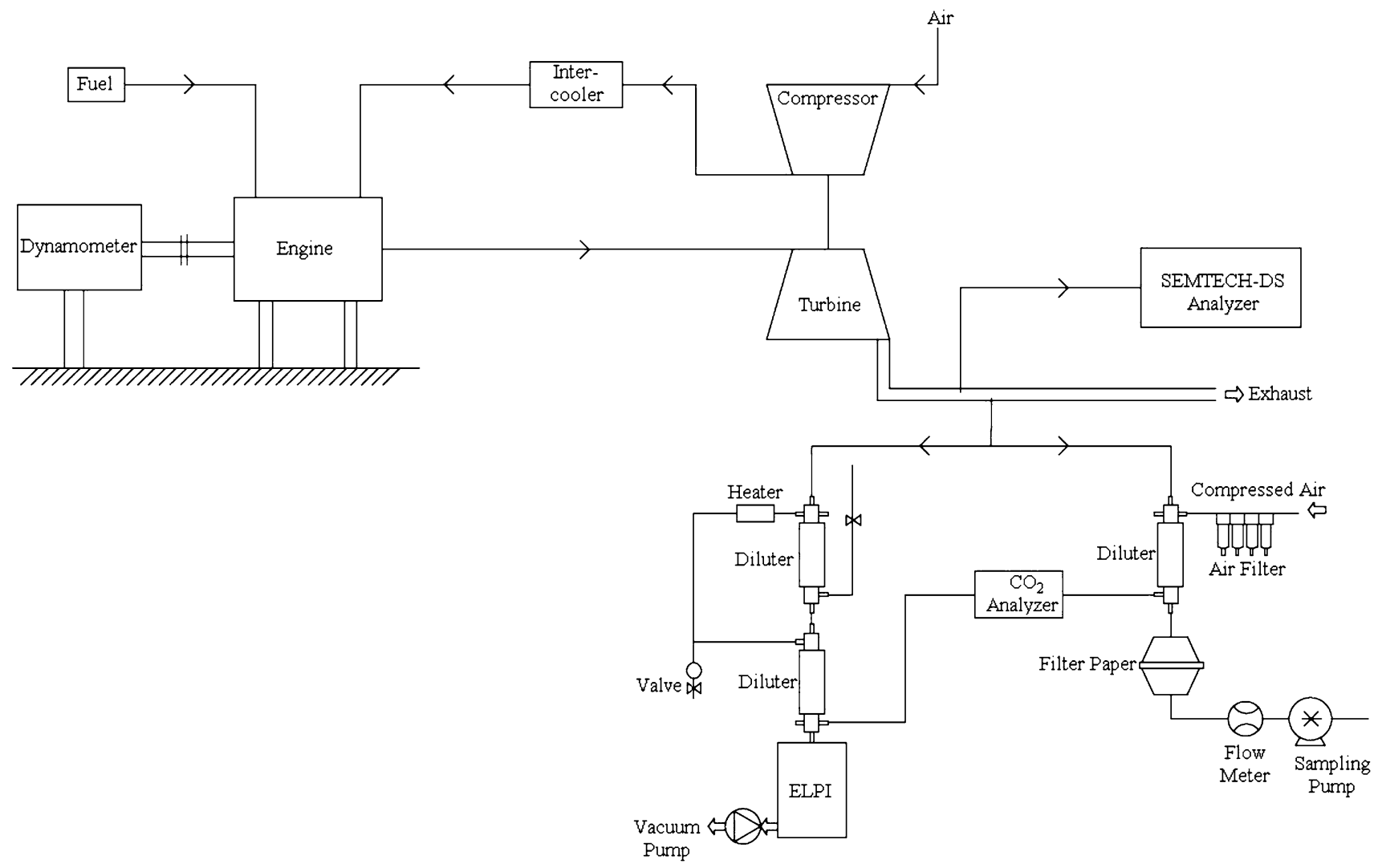

Fig. 1 Schematic diagram of test bench

The deviations were less than $12 \%$ for 15 measured TME $(n=3)$. The surrogate recoveries were from 77 to $108 \%$ in all the samples. The standard deviations were up to \pm 1.34 and \pm 1.23 for $\mathrm{NO}_{2} / \mathrm{NO}_{\mathrm{x}}$ ratio in case of diesel and biodiesel, respectively. Further, the standard deviations measured during the each case of pollutants have been shown for the corresponding cyclic modes.

\section{Results and discussion}

Emissions of accumulation mode particles

It is clear from Fig. 2 that the NPs emissions in accumulation mode are significantly lower with biodiesel as compared to conventional diesel throughout the cycle. The mean reduction rate varies from $22 \%$ at Mode 8 (idle mode) to $42 \%$ at Mode 2 (a higher load mode), which indicates that biodiesel plays a significant role in the controlling of accumulation mode particles. Furthermore, the emissions are higher at higher loads as compared to lower ones. Also, the NPs are higher at maximum speed modes, compared with the respective lower speed modes.

The higher reduction rates with biodiesel may be attributed to the higher nitrogen dioxide to nitrogen oxide ratios $\left(\mathrm{NO}_{2} / \mathrm{NO}_{\mathrm{x}}\right)$ with biodiesel as shown in Fig. 2. The oxygen content inherited by biodiesel plays an important role in the oxidation of $\mathrm{NO}$ to $\mathrm{NO}_{2}$, and thus in the formation of higher $\mathrm{NO}_{2} / \mathrm{NO}_{\mathrm{x}}$ ratio. The higher $\mathrm{NO}_{2} / \mathrm{NO}_{x}$ ratio may further prompt the combustion of soot and $\mathrm{SOL}$ of PM. It is well known that $\mathrm{NO}_{2}$ is strong oxidant of soot as compared to oxygen itself (Setiabudi et al. 2004), so both $\mathrm{NO}_{2}$ and oxygen $\left(\mathrm{O}_{2}\right)$ increase the soot combustion rates, and thus decrease the accumulation mode particles. It is worth mentioning that even $\mathrm{NO}_{2} / \mathrm{NO}_{\mathrm{x}}$ ratios are less at Mode 4 and Mode 8, still NPs abatements are observed with biodiesel as compared to diesel. However, these reductions are less significant as compared to those with higher $\mathrm{NO}_{2} / \mathrm{NO}_{\mathrm{x}}$ ratios at higher load modes. These lower reduction rates with biodiesel are likely due to the other physicochemical properties of biodiesel (such as lack of aromacy and lower sulfur content), which might be conducive to reduce the carbonaceous fraction of PM even at lower load modes. Consequently, the accumulation mode particles are decreased even at lower $\mathrm{NO}_{2} / \mathrm{NO}_{\mathrm{x}}$ ratio with biodiesel, relative to diesel.

The increased NPs, on the other hand, during higher loads with both the fuels may be due to the higher soot formation or incomplete combustion of carbonaceous PM owing to rich mixture or weak air-to-fuel ratios at higher 
Fig. 2 Number of particle emissions in accumulation mode as function of $\mathrm{NO}_{2} / \mathrm{NO}_{\mathrm{x}}$ ratio
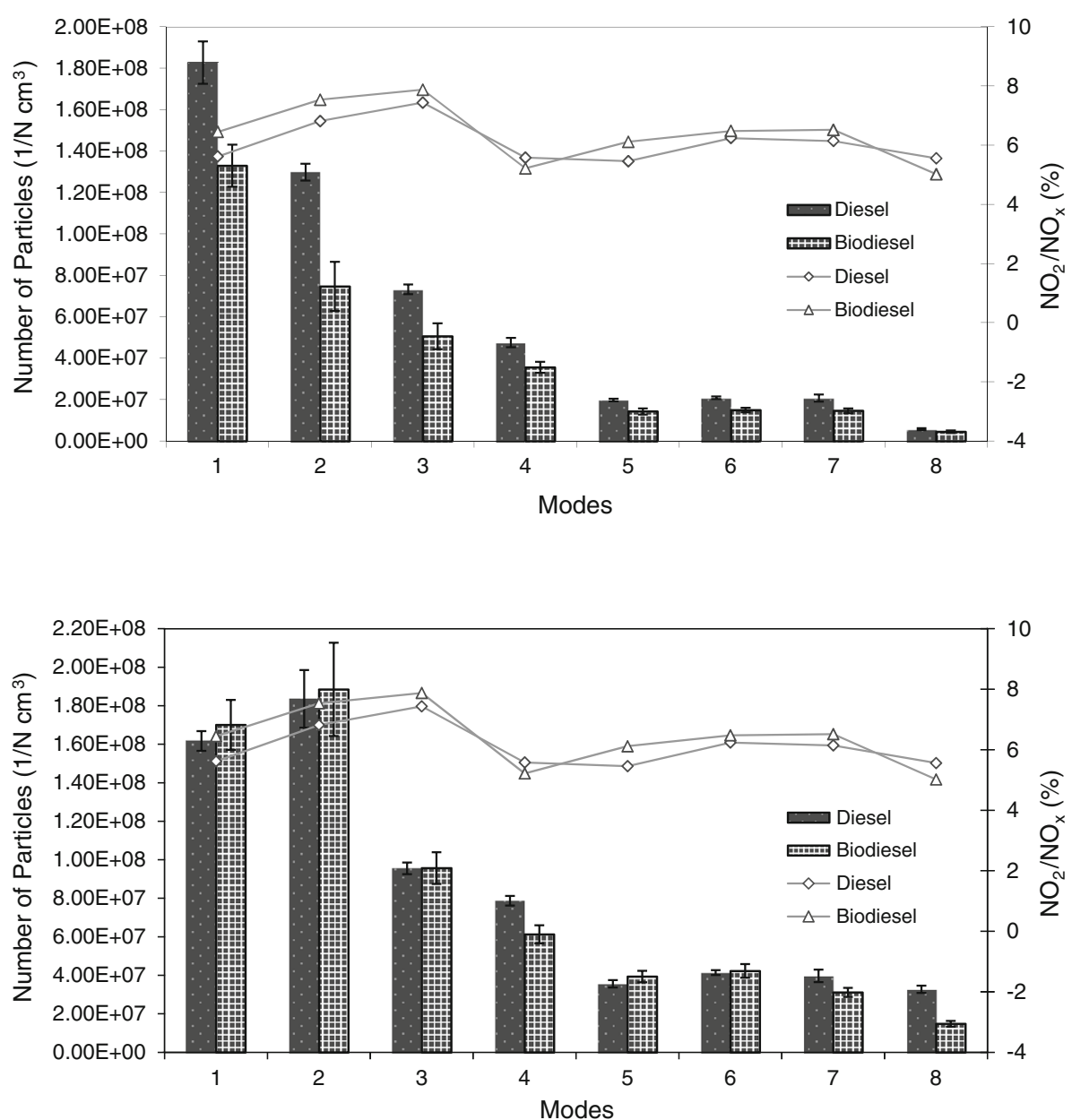

Fig. 3 Number of particle emissions in nucleation mode as function of $\mathrm{NO}_{2} / \mathrm{NO}_{\mathrm{x}}$ ratio loads relative to lower ones (Liu et al. 2011). Similarly, elevated NPs emissions at maximum speed modes with both the fuels are most likely again due to relatively higher soot formation caused by the decrease in oxidation rate, and thereby decrease in combustion temperature. Maximum speed can increase the turbulence in the combustion chamber, and thus can decrease the combustion temperature by increasing the heat losses (Collier et al. 1995).

\section{Emissions of nuclei mode particles}

Figure 3 presents the variation in number of particles in nuclei mode during various modes of the cycle. The NPs are $2-11 \%$ higher at higher load modes of both the maximum power and torque speeds with biodiesel, compared with diesel. Meanwhile, $\mathrm{NO}_{2} / \mathrm{NO}_{\mathrm{x}}$ ratios are also higher during the same modes with biodiesel leading to an important finding that unlike accumulation mode particles nanoparticles are not much affected by the $\mathrm{NO}_{2} / \mathrm{NO}_{\mathrm{x}}$ ratios.

The higher nano-particle emissions with biodiesel during higher loads are probably due to homogenous as well as heterogeneous nucleation. As discussed above in section "Emissions of accumulation mode particles" that the controlling of accumulation mode particles is directly related to $\mathrm{NO}_{2} / \mathrm{NO}_{\mathrm{x}}$ ratios, and thus to the combustion rates of soot. It is, however, worth noting that the formation of nanoparticles do not exhibit much relevance to $\mathrm{NO}_{2} / \mathrm{NO}_{\mathrm{x}}$ ratios. Further, it is conjectured that either sulfates or THC are involved in the formation of nuclei mode particles.

Armas et al. (2008) demonstrated that if volatile material cannot find soot for adsorption, it starts to condensate on HC surface. Thus, homogenous nucleation proliferates resulting in more and more nuclei mode particles. Moreover, the oxygen content in biodiesel may also play an important role in the initiation of heterogeneous nucleation. Although sulfur content is less in biodiesel compared with petroleum diesel, it is probable that available trace sulfur together with that present in lube oil was converted to $\mathrm{SO}_{2}$, and then to $\mathrm{SO}_{3}$ owing to the oxygen enrichment. Subsequently, the $\mathrm{SO}_{3}$ is transformed to sulfuric acid nuclei in the presence of water and diluting air, with the consequent adsorption phenomenon on such inorganic compounds 
(Liu et al. 2011). This is why nuclei mode particles are higher with biodiesel as compared to diesel, particularly at higher load modes. Further, it is also speculated that soluble organic fraction (SOF) was increased with biodiesel at higher loads due to which nucleation process expedited during the dilution, resulting in higher nuclei mode particles. Kati et al. (2004) have reported that the presence of SOF promotes the nucleation in the exhaust as it gets diluted in the exhaust pipe.

\section{Sulfate emissions}

Figure 4 shows the sulfate emissions with both the fuels. It is obvious that sulfates are higher with biodiesel relative to diesel. The mean relative increase varies 3-8\% during the cycle with the exception of $50 \%$ and idle load modes at which pollutants get decreased dramatically by $4-11$ and $17 \%$, respectively. It is of great concern to note that the modes during which nanoparticles were higher with biodiesel, the sulfates are higher too during the same. So the issue (raised in previous section) whether homogenous or heterogeneous nucleation is responsible for higher nuclei mode particles, is resolved now. It can easily be deduced that heterogeneous nucleation plays a definite role in the formation of nuclei mode particles as compared to homogenous nucleation in case of biodiesel.

Actually, oxygen enrichment in biodiesel oxidizes the available traces of sulfur to $\mathrm{SO}_{2}$ in a very similar way as it does in the oxidation of $\mathrm{NO}$ to $\mathrm{NO}_{2}$. This converted $\mathrm{SO}_{2}$, as discussed earlier, further actively participates in promoting the inorganic or heterogeneous nucleation. Thus, higher sulfate emissions with biodiesel are the outcome of sulfate nanoparticles formed during the nucleation process. However, the decrease in sulfate emissions with biodiesel during $50 \%$ load modes at both cyclic speeds (i.e., Mode 3 and Mode 7) is very interesting. Probably, it is the load level at which optimum air-to-fuel ratio occurs with biodiesel. At this load, more complete combustion takes place and the temperature is prone for the burning or combusting of PM, most importantly for sulfates and soot emissions.

\section{Trace metal emissions}

Although trace metal emissions are available only in traces from the engine exhaust, these are detrimental to human health due to their toxic potential (Becker et al. 2005). The TME comes largely from the lube oil, fuel, detergents, and additives (Zhao et al. 2010). A group comprising of crust elements like $\mathrm{Ca}, \mathrm{Fe}, \mathrm{Mg}, \mathrm{Al}$, and $\mathrm{Si}$ contributes about $82 \%$ of the total metal content in diesel fuel (Wang et al. 2003). The TME rates with both fuels are shown at various modes of the cycle in Fig. 5. In the meantime, the percentage reductions in TME with biodiesel are also shown. The mean TME are significantly reduced with biodiesel, and the reduction rates vary by $65-85.4 \%$ during the operating cycle. This reduction implies that biodiesel has rightly been known as environment friendly fuel owing to better physicochemical characteristics inherited by it.

On account of their significance to environment, the TME have further been discussed in terms of individual components measured at three important modes of the cycle (i.e., Mode 1, Mode 4, and Mode 5) as shown in Fig. 6. It is evident that $\mathrm{Fe}$ and $\mathrm{Ca}$ are the most abundant elements with diesel, while $\mathrm{Na}$ is the predominant trace metal with biodiesel during the selected modes of cycle. The mean relative decrease in $\mathrm{Fe}$ and $\mathrm{Ca}$ with biodiesel varies by $89-97.8$ and $77.6-87 \%$, respectively. However, the mean relative increase in Na varies by $29-46 \%$ with biodiesel. Moreover, some elements such as $\mathrm{K}, \mathrm{Mg}$, and Mn show either increasing or decreasing trends with biodiesel depending upon engine load and speed. For example, on the average, $\mathrm{K}$ increases by only 3.8 and $12 \%$ during
Fig. 4 Role of biodiesel in the alteration of sulfate emissions

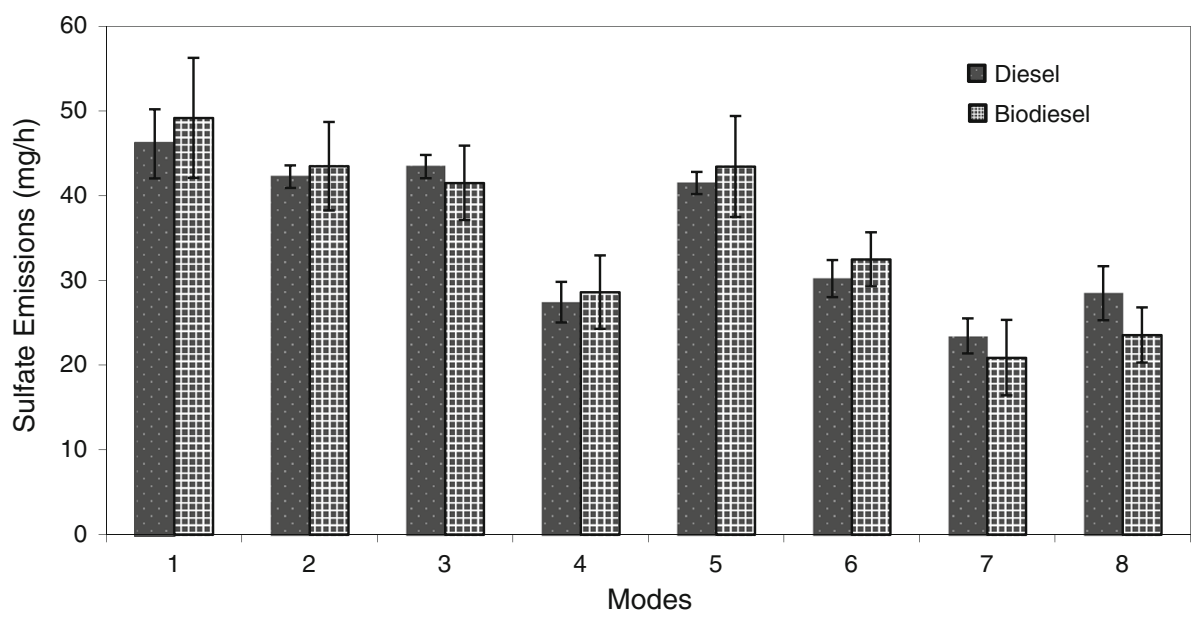


Fig. 5 Trace metal emissions and role of biodiesel on their reduction

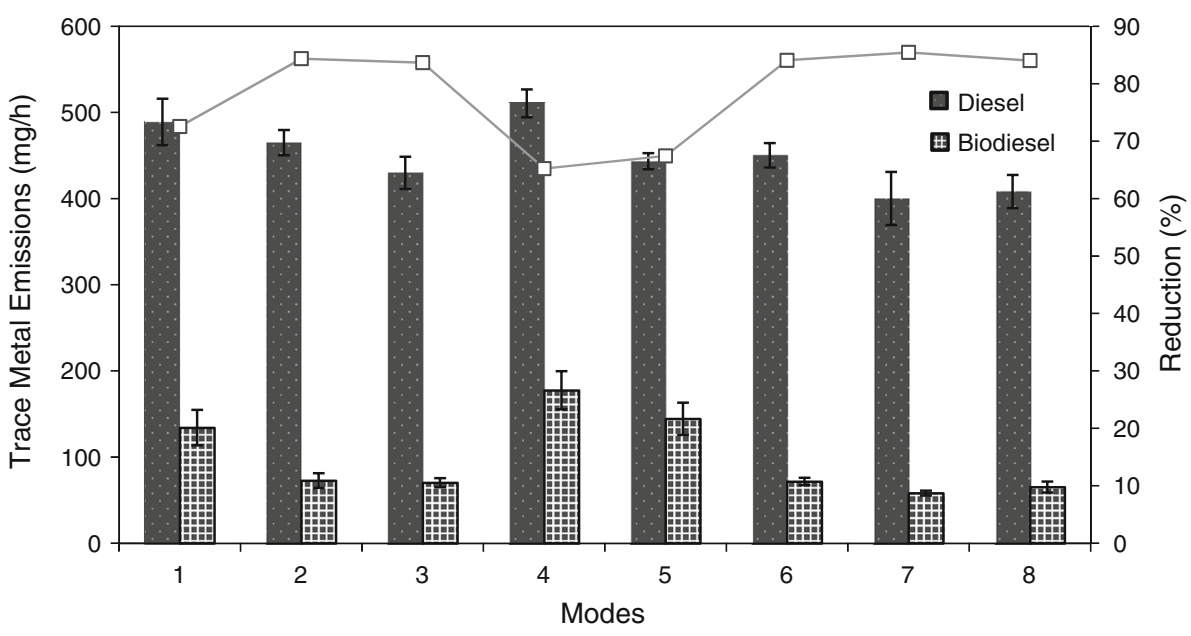

Mode 1 and Mode 4, respectively, but decreases up to $42 \%$ during Mode 5. Similarly, $\mathrm{Mg}$ and $\mathrm{Mn}$ exhibit respective maximum rise up to 27 and $46 \%$ during maximum load modes (Mode 1 and Mode 5); however, show diminution by 15 and $37.8 \%$ during minimum load mode (Mode 4) with biodiesel. All the remaining elements are either absent or decreased appreciably with biodiesel, relative to diesel fuel. Particularly, the reductions in $\mathrm{Zn}, \mathrm{Cr}$, and $\mathrm{Al}$ elements are remarkable.

The higher reduction rates in $\mathrm{Fe}$ emissions are most likely due to the decrease in engine wear with biodiesel as compared to diesel. It has been demonstrated that wear of various vital parts of engine such as cylinder liner, piston, piston rings, etc. are significantly reduced with biodiesel due to its additional lubricity (Agarwal 2007). The higher Ca emission rates in case of diesel may be attributed to its higher content in lubricating oil ( $>1,000 \mathrm{ppm})$. This higher content together with $\mathrm{Ca}$ and other additives of diesel fuel may have increased the $\mathrm{Ca}$ emissions. Although engine was operated with the same category of lubricant in case of biodiesel, $\mathrm{Ca}$ emissions were reduced possibly due to better oxidation rate with biodiesel. Further, the reduction in $\mathrm{Zn}$, $\mathrm{Cr}$, and $\mathrm{Al}$ emissions with biodiesel may be again due to the less abrasion of cylinder parts in case of biodiesel, compared with diesel. It has been reported that typical sources of $\mathrm{Zn}, \mathrm{Cr}$, and $\mathrm{Al}$ are abrasion or wear of various components such as bearings, brass components, seals, rings, cylinder liner, piston and additives (Agarwal et al. 2003).

On the other hand, the increased emission rates of $\mathrm{K}$ and $\mathrm{Na}$ with biodiesel may be due to the use of $\mathrm{NaOH}$ and $\mathrm{KOH}$ as catalyst in the transesterification of biodiesel. But it is interesting to note that unlike $\mathrm{Na}, \mathrm{K}$ shows varying emission trends with biodiesel i.e., both increasing as well as decreasing during the selected modes of the cycle. These trends are helpful in making a decision that $\mathrm{NaOH}$ was definitely used as catalyst instead of $\mathrm{KOH}$ because $\mathrm{Na}$ reveals much higher and uniform emission behavior as compared to $\mathrm{K}$. Moreover, the decreased emission rates of $\mathrm{Mg}$ and $\mathrm{Mn}$ in case of diesel may be due to the fact that it may contain lesser contents of them as compared to biodiesel. Basically, Mn is used in gasoline instead of diesel to obtain the better octane number (Cheung et al. 2010), rather than to improve cetane number. This is why baseline $\mathrm{Mg}$ and $\mathrm{Mn}$ emissions remained lower even during higher load modes.

\section{Conclusion}

The current study is aimed at the investigation of biodiesel role in the alteration of PM characteristics like accumulation and nuclei mode particles, sulfates, and trace metals. A turbocharged diesel engine was run on $\mathrm{AC}$ electrical dynamometer, first using diesel fuel and then biodiesel to measure the same categories of pollutants for their subsequent comparison. The $\mathrm{NO}$ and $\mathrm{NO}_{2}$ were measured using SEMTECH-DS, while accumulation as well as nuclei mode particles, sulfates and trace metals were known through ELPI, ion chromatography and ICP-atomic emission spectroscopy, respectively. Total four samples $(n=4)$ were collected for the each category of pollutants, so the results have been discussed on the basis of their mean values along with standard deviations. The deviations ranged \pm 1.34 and \pm 1.23 for $\mathrm{NO}_{2} / \mathrm{NO}_{\mathrm{x}}$ ratio with diesel and biodiesel, respectively.

Experimental results showed that the accumulation mode particles, on the average, were reduced by $22-42 \%$ with biodiesel owing to higher $\mathrm{NO}_{2} / \mathrm{NO}_{\mathrm{x}}$ ratios. On the contrary, nanoparticles were increased by $2-11 \%$ due to heterogeneous nucleation, regardless of $\mathrm{NO}_{2} / \mathrm{NO}_{\mathrm{x}}$ ratios. Further, the accumulation mode particles were 
Fig. 6 Comparison of individual trace metals and their reductions at a Mode $1, \mathbf{b}$ Mode 4, and $\mathbf{c}$ Mode 5
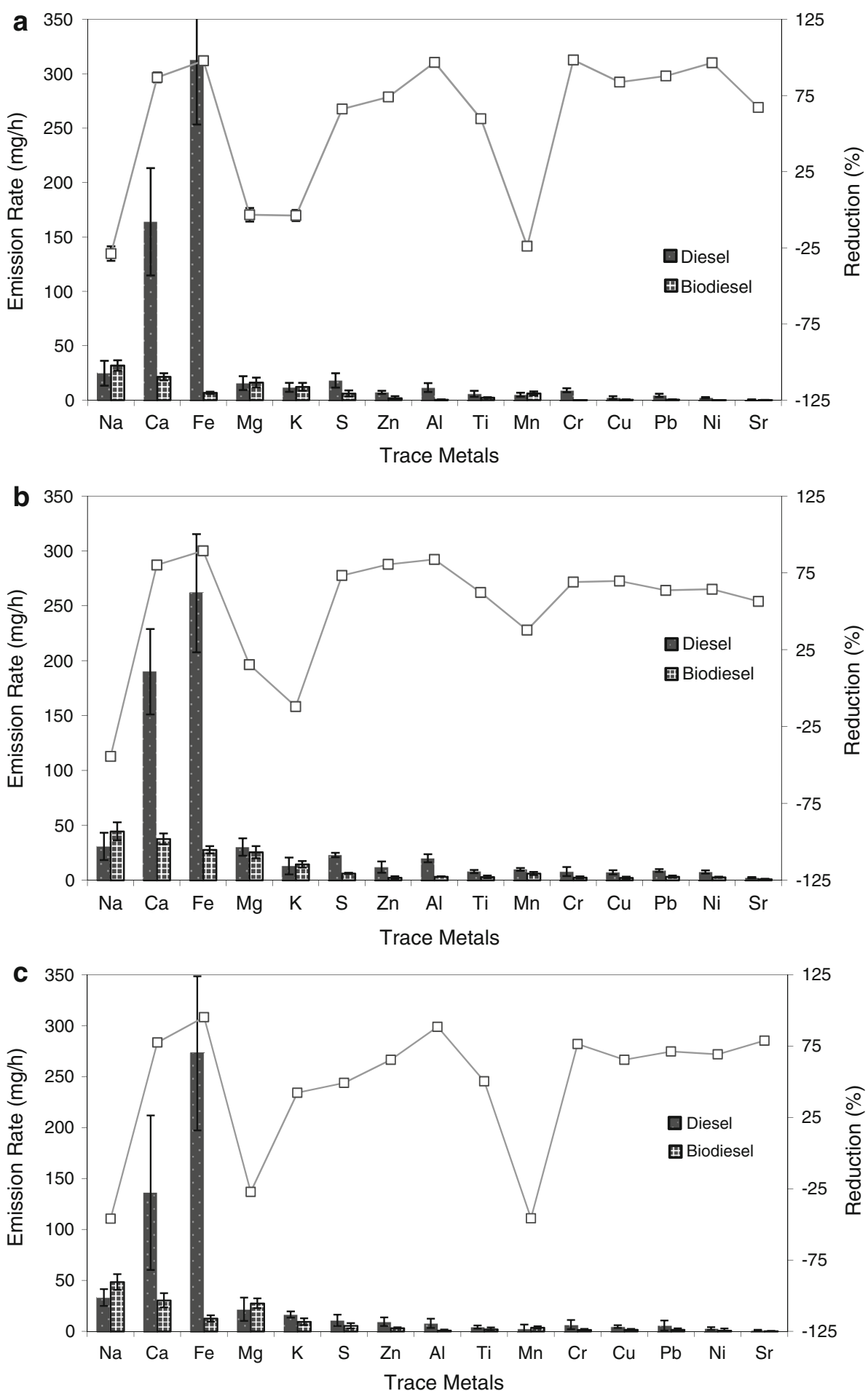

higher during higher loads as well as at maximum speed than those measured at corresponding lower levels of load and speed. In general, sulfates were 3-8\% higher with biodiesel relative to diesel, and a correlation was found between nanoparticles and sulfate emissions. Moreover, on the basis of their mean or average values, the TME were reduced by $65-85.4 \%$ with biodiesel as compared to diesel. In addition to this, $\mathrm{Fe}, \mathrm{Ca}$ and $\mathrm{Na}$ 
were the most abundant elements from the engine exhaust. Both $\mathrm{Fe}$ and $\mathrm{Ca}$ elements were decreased by 89-97.8 and 77.6-87\%, respectively, while $\mathrm{Na}$ increased by $29-46 \%$ with biodiesel. The elements such as $\mathrm{Zn}, \mathrm{Cr}$ and $\mathrm{Al}$ exhibited marked reduction in the case of biodiesel. However, trace metals $\mathrm{K}, \mathrm{Mg}$ and $\mathrm{Mn}$ revealed random trends with both the fuels depending upon the engine load and speed.

Acknowledgments Authors would like to thank the laboratory staff for their help in conducting the experiments. Our sincere gratitude towards Dr. He Chao and Liu Zhi-hua for their support related to engine operation and ion chromatography. This work is financially supported by the National Natural Science Foundation (NNSF) of China under Grant \# 50576063. In the end, authors are thankful to the editor and the reviewers for their constructive comments.

\section{References}

Agarwal AK (2007) Biofuels (alcohols and biodiesel) applications as fuels for internal combustion engines. Prog Energ Combust 33: 233-271

Agarwal AK, Das LM (2001) Biodiesel development and characterization for use as a fuel in compression ignition engine. J Eng Gas Turbines Power 123(2):440-447

Agarwal AK, Rajamanoharan K (2009) Experimental investigations of performance and emissions of Karanja oil and its blends in a single cylinder agricultural diesel engine. Appl Energ 86: $106-112$

Agarwal AK, Bijwe J, Das LM (2003) Effect of biodiesel utilization of wear of vital parts in compression ignition engine. J Eng Gas Turbines Power 125(2):604-611

Agarwal D, Sinha S, Agarwal AK (2006) Experimental investigation of control of $\mathrm{NO}_{x}$ emissions in biodiesel-fueled compression ignition engine. Renew Energy 31:2356-2369

Armas O, Ballesteros R, Gomez A (2008) The effect of diesel engine operating conditions on exhaust particle size distributions. Proc Inst Mech Eng Part D J Auto Eng 222:1513-1525

Becker S, Dailey LA, Soukup JM, Grambow SC, Devlin RB, Huang YC (2005) Seasonal variations in air pollution particle-induced inflamatory mediator release and oxidative stress. Environ Health Persp 113:1032-1038

Cheung KL, Ntziachristos L, Tzamkiozis T, Schauer JJ, Samaras Z, Moore KF, Sioutas C (2010) Emission of particulate trace elements, metals and organic species from gasoline, diesel, and biodiesel passenger vehicles and their relation to oxidative potentials. Aerosol Sci Technol 44:500-513

Collier AR, Rhead MM, Trierand CJ, Bell MA (1995) Polycyclic aromatic compound profiles from a light-duty direct-injection diesel engine. Fuel 74:362-367

Donaldson K, Li XY, MacNee W (1998) Ultrafined (manometer) particle mediated lung injury. J Aerosol Sci 29:553-560

Dorado MP, Ballesteros E, Arnal JM, Gomez J, Gimenez FJ (2003) Testing waste olive oil methyl ester as a fuel in a diesel engine. Energy Fuels 17:1560-1565

Frampton MW (2001) Systemic and cardiovascular effects of airways injury and inflammation: Ultrafine particle exposure in humans. Environ Health Persp 109:529-532
He C, Ge YS, Tan JW, You KW, Han XK, Wang JF, You Q, Shah AN (2009) Comparison of carbonyl compounds emissions from diesel engine fueled with biodiesel and diesel. Atmos Environ 43:3657-3661

Jha SK, Fernando S, Filip TS (2008) Flame temperature analysis of biodiesel blends and components. Fuel 87:1982-1988

Jung H, Kittleson DB, Zachariah MR (2006) Characteristics of SME biodiesel-fueled diesel particle emissions and the kinetics of oxidation. Environ Sci Technol 40(16):4949-4955

Kati V, Annele V, Jyrki R, Jorma K (2004) Effect of after-treament system on size distribution of heavy duty diesel exhaust aerosol. SAE Tech pap Ser No. 2004-01-1980

Kittelson DB, Watts WF, Johnson JP, Rowntree CJ, Goodier SP, Payne MJ, Preston WH, Warrens CP, Ortiz M, Zink U, Georsmann C, Twigg MV, Walker AP (2006) Driving down on-highway particulate emissions. SAE Tech pap Ser No. 2006-01-0916

Lapuerta M, Armas O, Ballesteros R (2002) Diesel particulate emissions from biofuels derived from Spanish vegetable oils. SAE Tech pap Ser No. 2002-01-1657

Lapuerta M, Armas O, Rodriguez FJ (2008) Effect of biodiesel fuels on diesel engine emissions. Prog Energ Combust Sci 34:198-223

Lim M, Ayoko G, Morawska L, Ristovski Z, Jayaratne E, Kokot S (2007) The effects of fuel characteristics and engine operating conditions on the elemental composition of emissions from heavy duty diesel buses. Fuel 86:1831-1839

Lin YC, Lee WJ, Wu TS, Wang CT (2006) Comparison of PAH and regulated harmful matter emissions from biodiesel blends and paraffinic fuel blends on engine accumulated mileage test. Fuel $85: 2516-2523$

Liu ZH, Shah AN, Ge YS, Ding Y, Tan JW, Jiang L, Yu L, Zhao W, Wang C, Zeng T (2011) Effects of continuously regenerating diesel particulate filters on regulated emissions and number-size distribution of particles emitted from a diesel engine. J Environ Sci 23:798-807

Nemmar A, Hoet PH, Vanquickenborne B, Dinsdale D et al (2002) Passage of inhaled particles into the blood circulation in humans. Circulation 105:411-414

Schneider J, Hock N, Weimer S, Borrman S, Kirchner U, Vogt R, Scheer V (2005) Nucleation particles in diesel exhaust: Composition inferred from In Situ mass spectrometric analysis. Environ Sci Technol 39:6153-6161

Setiabudi A, Makkee M, Moulijn JA (2004) The role of $\mathrm{NO}_{2}$ and $\mathrm{O}_{2}$ in the accelerated combustion of soot in diesel exhaust gases. Appl Catal B-Environ 50:185-194

Sierra Club of Canada, Eastern Canada Chapter (2003) The public health impact of diesel particulate matter (easterncanadchapter@ sierraclub.ca)

Song J, Alam M, Boehman AL, Kim U (2006) Examination of the oxidation behavior of biodiesel soot. Combust Flame 146(4): 589-604

Szybist JP, Song J, Alam M, Boehman AL (2007) Biodiesel combustion, emissions and emission control. Fuel Process Technol 88:679-691

Turrio-Baldassarri L, Battistelli CL, Conti L, Crebelli R, De Berardis B, Iamiceli AL, Gambino M, Iannaccone S (2004) Emission comparison of urban bus engine fueled with diesel oil and biodiesel blend. Sci Total Environ 327:147-162

Wang YF, Huang KL, Chun TL, Mi HH, Luo JH, Tsai PJ (2003) Emissions of fuel metals content from a diesel vehicle engine. Atmos Environ 37:4637-4643 
Wong CP, Chan TL, Leung CW (2003) Characterization of diesel exhaust particle number and size distributions using minidilution tunnel and ejector-diluter measurement techniques. Atmos Environ 37:4435-4446
Zhao H, Ge Y, Wang X, Tan J, Wang A, You k (2010) Effects of fuel sulfur content and diesel oxidation catalyst on PM emitted from light-duty diesel engine. Energy Fuels 24:985-991 